\title{
Letter from the Editors
}

\section{Dear readers,}

Welcome to Edentata 21! This year's issue features two full articles, two short communications, and two field notes. It includes an interesting review on the xenarthrans of Honduras; a description of the first camera trap records of giant anteaters in Baritú National Park, Argentina; and a report on the occurrence of ticks on free-ranging armadillos in Piauí, Brazil. Coincidentally, there are two contributions about giant armadillos and bees. One of them describes the attack of Priodontes maximus on a nest and its predation of stingless bees, whereas the other explores ways to reduce the conflict between beekeepers and giant armadillos. And don't miss the field note about the SlothBot, a cute environmental monitoring robot! Hopefully, the SlothBot will collect data for field ecologists in the rainforest canopy in the near future.

The News section includes, among others, exciting announcements about the partnership our Specialist Group has entered into with Nurtured by Nature, and the possibility to support our Specialist Group via PayPal. It also showcases some astonishing statistics from the First International Congress on Xenarthra Conservation, which was held online from November 30 to December 3 and was attended by over 500 participants! We hope many of you participated in this amazing congress and enjoyed the interesting talks and minicourses. We would like to take the opportunity to thank Instituto Tamanduá for having organized this wonderful event. This was the first, but certainly not the last, International Congress on Xenarthra Conservation.

At the end of this edition, you will find updated Instructions to Authors in English, Spanish and Portuguese. We hope that these detailed instructions will help you prepare your manuscripts for submission to Edentata. We are looking forward to receiving your manuscripts!

Last, but not least, we would like to thank Benison Pang for his generous donation, which has allowed us to prepare this year's edition of Edentata, and Kansas City Zoo for their generous donation to the Pygmy Sloth Conservation Program. We are also grateful to Nurtured by Nature for their continuing support. 


\section{IUCN SSC Anteater, Sloth and Armadillo Specialist Group Members 2017-2020}

Chair

Mariella Superina, Dr.med.vet., Ph.D. in

Conservation Biology

Research Scientist CONICET

Associate Researcher Fundación Omacha

IMBECU, CCT CONICET Mendoza

Casilla de Correos 855

Mendoza (5500)

Argentina

E-mail:mariella@superina.ch

\section{Deputy Chair}

Nádia de Moraes-Barros, Ph.D. in Biology

(Genetics)

Auxiliary Researcher

$\mathrm{CiBIO}$ - Centro de Investigação em

Biodiversidade e Recursos Genéticos/InBIO

Laboratório Associado

Universidade do Porto

Campus Agrário de Vairão

Rua Padre Armando Quintas

4485-661 Vairão

Portugal

E-mail: nadiabarros@cibio.up.pt

\section{Red List Authority}

Agustín M. Abba, Doctor in Natural Science

Research Scientist CONICET

Centro de Estudios Parasitológicos y Vectores

(CEPAVE)

CCT - CONICET La Plata - UNLP

Bv. 120 S/N entre Avenida 60 y Calle 64

La Plata (1900)

Argentina

E-mail:abbaam@yahoo.com.ar
Members

Agustín M. Abba, Argentina

Roberto Aguilar, USA

Teresa Cristina Anacleto de Silveira, Brazil

María Clara Arteaga, Mexico

Lizette Bermúdez, Peru

Adriano Chiarello, Brazil

Gustavo A. B. da Fonseca, USA

Frédéric Delsuc, France

Flávia Miranda, Brazil

John Gramieri, USA

Jutta Heuer, Germany

Rachel Hoffmann, United Kingdom

Jim Loughry, USA

Colleen McDonough, USA

Dennis A. Meritt Jr., USA

Nadia Moraes-Barros, Brazil/Portugal

Andrew Noss, USA

Tinka Plese, Colombia

Monique Pool, Suriname

Virgilio G. Roig, Argentina

Ilona Schappert, Germany

Diorene Smith, Panama

Paul Smith, Paraguay

Mariella Superina, Argentina

Sergio F. Vizcaíno, Argentina

Bryson Voirin, Germany 